\title{
LOS MODELOS DE SENADO'1
}

\author{
POR \\ JOSÉ MARÍA MORALES ARROYO \\ Profesor Titular de Derecho Constitucional \\ Universidad de Sevilla
}

\section{INTRODUCCIÓN: UN RECORDATORIO DE LOS ELEMENTOS FUNDACIONALES DEL SENADO ESPAÑOL}

En un trabajo reciente TORRES DEL MORAL rememoraba los intereses básicos que se entrecruzaron en el momento constituyente a la hora de configurar el Senado. Se trataba entonces de, a partir de un cierto prejuicio bicameralista, satisfacer a un tiempo indeterminados intereses territoriales y establecer una Cámara conservadora que contuviera la voluntad del Congreso de los Diputados. Sin embargo, al final se construyó un Senado "en el que casi desapareció su carácter territorial y se acentuó su naturaleza conservadora»².

La doctrina que ha reflexionado durante los veinticinco años de vigencia del texto constitucional, y aunque tampoco han faltado trabajos elogiando sus virtudes ${ }^{3}$, mayoritariamente se ha inclinado por destacar

1 Una primera versión más reducida de este trabajo se presentó como ponencia en el VIII Congreso Iberoamericano de Derecho Constitucional, celebrado en la Universidad de Sevilla durante la primera semana de diciembre de 2003.

2 Antonio ToRRes del Moral: "Veinticinco años de Senado», en Revista de Derecho Político, 58-59 (2003-2004), pp. 483-485; la cita literal se encuentra en la página 484.

3 En la línea más continuada en la defensa de la institución senatorial se deben reseñar los trabajos de Piedad García Escudero y de Benigno Pendás, entre otros «EI Senado en el sistema constitucional español: realidades y perspectivas" en Revista de las Cortes Generales, 2 (1985) y "El Senado Cámara de integración territorial», en Las Cortes, vol. II, (Madrid: Dirección General de lo Contencioso, 1987); así como los 
la existencia de elementos disfuncionales en su diseño normativo y en la práctica que de él se ha derivado, ya sea por su heterogénea composición, por el incumplimiento de su supuesto fin territorial, por su casi nula capacidad integradora o por otros motivos ${ }^{4}$.

Por otro lado, existe coincidencia en señalar el desequilibrio competencial como un principio estructural en la definición constitucional del bicameralismo español, que según conclusión de FRANCESC DE CARRERAS ha convertido al Senado en "una Cámara sin funciones decisorias desde el punto de vista legislativo y con funciones secundarias desde los otros puntos de vista $»^{5}$. La desigualdad competencial entre el Congreso de los Diputados y el Senado ha hecho que algunos autores se hayan mostrado comprensivos con la baja calidad de nuestro modelo de Cámara alta y a la mayoría les ha permitido confeccionar críticas sobre la imposibilidad de cumplir el mandato constitucional de la "territorialidad", en la medida que el debilitamiento funcional afectaba también al ejercicio de funciones relacionadas con las Comunidades Autónomas.

El acuerdo doctrinal también ha alcanzado a la consideración del Senado como una Cámara débil en el binomio orgánico sobre el que se construyen nuestras Cortes Generales frente a la Cámara fuerte, el Congreso de los Diputados 6 . Por cerrar el círculo, volviendo a los orígenes del texto constitucional, se puede aceptar que, «en definitiva, la

trabajos en solitario de la primera autora: Los senadores designados por las Comunidades Autónomas (Madrid: CEC, 1995) y "La Comisión General de la Comunidades Autónomas (reforma del Reglamento del Senado)" en Revista Vasca de Administración Pública, 133 (1994).

${ }^{4}$ Como señalara CHUeCA, "el Parlamento resultante, siendo bicameral, era producto de diversos bicameralismos y por tanto esencialmente híbrido. El principio conservador deducible del posible desacuerdo entre las dos Cámaras quedaba desnaturalizado por un sistema electoral que hacía prácticamente imposible la distorsión entre la composición de ambas Cámaras". "Teoría y práctica del bicameralismo en la Constitución española», en Revista Española de Derecho Constitucional, 10 (1984), p. 79.

5 "El Senado en la Constitución española», en F. Pau i Vall (cood.): El Senado, Cámara de representación territorial (Madrid: Tecnos y AELPA, 1996), p. 37.

6 Parece claro que el constituyente español no deseaba un Senado fuerte como el que se ha implantado en ciertos ordenamientos constitucionales como el norteamericano o el alemán; o como en los sistemas políticos iberoamericanos que han seguido, con perfiles propios, el modelo de Cámara alta alumbrado en el bicameralismo del constitucionalismo norteamericano. En este último grupo se pueden incluir por diferentes motivos y con distintos grados de "fortaleza" el Senado de Argentina, el Senado Federal de Brasil, el Senado de Chile, o la Cámara de Senadores de Méjico. 
opción tomada por el constituyente fue producto de una fórmula de tipo "suma cero": los sectores conservadores querían preservar un Senado de composición rural con funciones moderadoras; los sectores progresistas estaban de acuerdo con ello siempre que no otorgaran a un Senado así configurado funciones decisivas" ${ }^{7}$.

En consecuencia, como resulta a estas alturas de sobra conocido, el Senado español partía de una posición institucional debilitada al carecer de instrumentos para exigir responsabilidades al Gobierno (art. 108 CE) y no distinguirse del Congreso de los Diputados a la hora de ser destinatarios de una eventual disolución anticipada (arts. 99.5 y $115 \mathrm{CE}$ ), mientras que no se establecían diferencias en el tiempo de duración del mandato de ambas Cámaras. Pero, además, encontraba limitadas sus facultades legisladoras en tanto que se le otorgaba una posición secundaria en el procedimiento de creación de la Ley, sin, por otro lado, participar en la convalidación de los decretos-leyes (art. 86.2 $\mathrm{CE})$ y quedaba indeterminada y disminuida su participación durante el desarrollo de los estados de excepción (art. $116 \mathrm{CE}$ ). Por último, los conflictos entre los órganos colegisladores, incluso durante el proceso de reforma constitucional, se resolvían de manera favorable a la posición adoptada por la Cámara baja.

La práctica política española tampoco había posibilitado una consolidación de la institución senatorial. Ya desde los primeros momentos de la andadura constitucional se advirtió que la forma de seleccionar a los senadores mayoritariamente a través de un sistema electoral con tendencia a reproducir los resultados del Congreso de los Diputados -el "efecto multiplicador", en términos de CHUECA ${ }^{8}$ - y la línea hacia la simplificación detectada en el sistema de partidos tendrían como consecuencia la homogeneización de la composición política de ambas Cámaras. Por ello, la reproducción de mayorías y minorías harían indistinguibles las voluntades de tales Asambleas e improbables los conflictos intraparlamentarios. En este sentido, escribía SOLÉ TURA en agosto de 1978, teniendo aún como referencia el artículo 64 del Proyecto constitucional,

"¿Qué sentido tiene un Senado de estas características? Ninguno, como no sea el afán de los dos partidos hoy mayoritarios de tener una Cámara en la que por el juego del sistema de elección se repartirán entre ellos el mayor número de senadores. Es decir, no hay más explicación

7 F. DE CaRRERAS: «El Senado en la Constitución española», cit., p. 32.

8 Op. cit., p. 81. 
que el deseo de impulsar por vía electoral la pretendida tendencia al bipartidismo" ${ }^{9}$.

El inicio de la Octava Legislatura ha descubierto dos líneas de interés sobre el Senado. De nuevo en la vida política se ha desempolvado el debate sobre la necesidad de proceder a la reforma de la Constitución con el objetivo de conceder una nueva configuración a la Segunda Cámara. Pero, además, la composición de las Cortes Generales tras las elecciones del 14 de marzo de 2004 por primera vez ha dado como resultado la polarización de la voluntad de ambas Cámaras que manifiestan mayorías distintas y encontradas, por lo que se augura una legislatura en la que el Senado puede adoptar un papel de Cámara de bloqueo.

Las páginas que siguen intentarán aportar alguna idea al debate abierto durante en el presente mandato mediante la valoración de los modelos que cronológicamente ha ido asumiendo el Senado y los problemas que han planteado, especialmente durante la Séptima Legislatura. Para, con posterioridad, apuntar algunas reflexiones finales sobre las expectativas que se han abierto con la estructuración política que ha consolidado durante la VIII Legislatura.

\section{LA CONSOLIDACIÓN PRÁCTICA DEL MODELO SENATORIAL}

La realidad ha caminado preponderantemente en la dirección apuntada por la doctrina. Únicamente en contadas ocasiones y por motivos puntuales el Senado se ha convertido en un "peligro" para la mayoría gubernamental. En la Primera Legislatura (1979-1982) la inestabilidad del partido gubernamental paradójicamente llevó al Gobierno en ocasiones a utilizar la Cámara alta, en la que de partida gozaba de una mayoría más cómoda ${ }^{10}$, para tomarse una cierta tregua y corregir el con-

9 Para más tarde concluir: «Finalmente, ese Senado tiende a fomentar una bipolarización de las fuerzas políticas que no sólo es ajena a la auténtica realidad del país, sino que se contrapone a las necesidades políticas de España en el futuro a corto y a largo plazo». Jordi Solé Tura: «El Congreso y el Senado en el Proyecto de Constitución", en El País, de 31 de agosto de 1978. En términos de Pedro CRUZ, "la composición del Senado fue, como se sabe, el precio que hubo que pagar por la composición del Congreso", en "Una nota sobre el Senado como Cámara de representación territorial", ahora en La curiosidad del jurista persa, y otros estudios sobre la Constitución (Madrid: Centro de Estudios Políticos y Constitucionales", 1999), p. 375; con la adenda de que «es un precio que ha venido pesando como una losa sobre la legitimidad democrática de esta Cámara».

10122 senadores electos para el Grupo de Unión de Centro Democrático y 79 senadores para los diferentes Grupos de la esfera socialista. 
tenido de ciertas normas cuya tramitación había provocado alboroto y división en sus filas cuando se debatieron en el Congreso de los Diputados. Durante los Gobiernos socialistas las mayorías en el Senado fueron cómodas hasta la Quinta Legislatura, momento en el que dentro del Congreso se apoya en una limitada coalición a partir de 159 diputados y en el Senado la diferencia se reduce a su mínima expresión y cambia de proporción en los momentos finales ${ }^{11}$. Por último, la tendencia se ha mantenido en las Sexta y Séptima Legislaturas con las mayorías populares con 112 y 127, respectivamente, electos para el Partido Popular frente a 81 y a 61 senadores elegidos a partir de las candidaturas del PSOE.

La preponderancia en la distribución de fuerzas y especialmente las distancias entre el partido de la mayoría y el principal partido de la oposición en ambas Cámaras también presenta una regular similitud a lo largo de las diferentes Legislaturas agotadas hasta la fecha por las Cortes Generales.

Mayorías de Unión de Centro Democrático

\begin{tabular}{c|c|c|c}
\hline Legislatura & & UCD & $P S O E$ \\
\hline \multirow{2}{*}{$\begin{array}{c}\text { Primera } \\
\text { Legislatura }\end{array}$} & Congreso & 168 & 121 \\
\cline { 2 - 4 } & Senado & 122 & 79 \\
\hline
\end{tabular}

Mayorías Socialistas

\begin{tabular}{c|c|c|c}
\hline Legislatura & & Socialistas & Populares \\
\hline \multirow{2}{*}{$\begin{array}{c}\text { Segunda } \\
(1982-1986)\end{array}$} & Congreso & 202 & 106 \\
\cline { 2 - 4 } & Senado & $\mathbf{1 3 4}(138)$ & $\mathbf{5 4}(58)$ \\
\hline $\begin{array}{c}\text { Tercera } \\
(1986-1989)\end{array}$ & Congreso & 184 & 84 \\
\cline { 2 - 4 } & Senado & $\mathbf{1 2 4}(147)$ & $\mathbf{6 3}(64)$ \\
\hline $\begin{array}{c}\text { Cuarta } \\
(1989-1993)\end{array}$ & Congreso & 175 & 106 \\
\cline { 2 - 4 } & Senado & $\mathbf{1 0 8}(124)$ & $\mathbf{7 7}(86)$ \\
\hline $\begin{array}{c}\text { Quinta } \\
(1993-1996)\end{array}$ & Congreso & 159 & 141 \\
\cline { 2 - 4 } & Senado & $\mathbf{9 6}(116)$ & $\mathbf{9 3}(105)$ \\
\hline
\end{tabular}

11 EI PSOE logra 96 escaños a través del sufragio directo a los que se añaden otros veinte a partir de la elección por los parlamentos de las Comunidades Autónomas y el Partido Popular parte de 93 electivos para lograr en los inicios de la Legislatura la formación de un Grupo parlamentario con 105 miembros. 
Mayorías Populares

\begin{tabular}{c|c|c|c}
\hline Legislatura & & Populares & Socialistas \\
\hline Sexta & Congreso & 154 & 141 \\
\cline { 2 - 4 }$(1996-2000)$ & Senado & $\mathbf{1 1 2 ( 1 3 3 )}$ & $\mathbf{8 1}(97)$ \\
\hline Séptima & Congreso & 179 & 125 \\
\cline { 2 - 4 }$(2000-2004)$ & Senado & $\mathbf{1 2 7}(150)$ & $\mathbf{6 1}(69)$ \\
\hline
\end{tabular}

Las tablas anteriores se han construido teniendo en cuenta principalmente los 208 Senadores que proceden de la elección directa en las diversas circunscripciones previstas en el artículo 69 de la Constitución. No obstante, esas cifras suelen incrementarse con posterioridad a medida que se produce el nombramiento de los senadores autonómicos - según el dato numérico que se aporta entre paréntesis- ${ }^{12}$. Pero, por sí mismas resultan lo suficientemente demostrativas, en primer lugar, de la preponderancia que tienen los dos principales partidos en apoyo nacional dentro del Senado y, en segundo lugar, de la distancia cómoda que suele establecerse entre el partido mayoritario (de Gobierno en todas las ocasiones) y la principal minoría de las Cortes Generales.

Mientras que los dos grandes partidos han controlado, dependiendo de la legislatura, entre el 76,57 por ciento y el 87,99 por ciento de los escaños del Congreso de los Diputados, han llegado, en cambio, a controlar entre el 86,63 por ciento y el 94,38 por ciento de los puestos que en el Senado se integraban a través de sufragio universal ${ }^{13}$.

Con respecto al otro doble mito iniciático en la andadura de nuestra segunda Cámara, en virtud del cual, de un lado, una mayoría en el

12 Así los socialistas incrementaron sus escaños hasta 138 (II), 147 (III), 124 (IV), 116 (V), 97 (VI) y 69 (VII) y los populares hasta 58 (II), 64 (III), 86 (IV), 105 (V), 133 (VI) y 150 (VII). También debe apuntarse la salvedad de que varios de los senadores integrados durante la Séptima Legislatura en el Grupo Entesa Catalana de Progrés proceden del Partido Socialista de Cataluña.

13 Dado que no es la finalidad de este trabajo efectuar un análisis desde la ciencia política de los cambios que se han producido en la composición del Congreso y el Senado, sí puede ser de interés dejar constancia de los datos porcentuales de ese dominio. En la I Legislatura entre UCD y PSOE, controlan el 82,57 por ciento y el 86,63 por ciento de los escaños en el Congreso y en el Senado. Los datos de las legislaturas de mayoría socialista son 87,94 frente a 94,38 en la Segunda, 76,57 frente a 89,89 en la Tercera, 80,28 frente a 88,93 en la Cuarta, y 85,70 frente a 90,86 en la Quinta. Por último, los porcentajes en las legislaturas de mayoría popular son 84,28 frente 92,78 en la Sexta y 86,85 frente a 90,37 en la Séptima. 
Congreso de los Diputados se acentuaba en el Senado y, de otro lado, el Senado iba a caracterizarse por su tendencia conservadora, las cosas tampoco han resultado tan sencillas de explicar.

Una vez descartado el análisis de la peculiar Primera Legislatura, que manifestó una dinámica propia, se constata que las dos primeras mayorías absolutas del Partido Socialista (Legislaturas II y III) se consolidaron en ambas Cámaras ${ }^{14}$ y que, cuando se produce un cambio en dicha situación en el Congreso, también se verifica la pérdida de la mayoría absoluta en el Senado. En el período de la mayoría absoluta la distancia porcentual que separa a la fuerza del Gobierno y a la principal minoría se manifiesta mayor en el Senado ${ }^{15}$, que en el Congreso de los Diputados ${ }^{16}$. No obstante, se comprueba también, que cuando comienza a erosionarse la ventaja socialista, el distanciamiento entre la mayoría y la principal fuerza política de la oposición se mantiene más firme en el Congreso de los Diputados que en el Senado. La tendencia descendente quedaba en cierta medida amortiguada por la mayor proporcionalidad demostrada por el sistema electoral del Congreso ${ }^{17}$, mientras que se señalaba de una forma más nítida en el Senado por la acción del sistema mayoritario que va a anunciar con anterioridad el cambio definitivamente registrado en $1996^{18}$.

El cambio de mayorías que tiene lugar en las Sexta y Séptima Legislaturas se plasma de una manera más radical en la composición del Senado que en la del Congreso. La distancia que separa a la mayoría del gobierno y al principal partido de la oposición en el Congreso asciende a un 3,72 puntos en la Sexta y a un 15,43 en la Séptima, mientras que en similares períodos la composición del Senado manifiesta una separación de 15 puntos entre senadores electos (13,9 por ciento tras la incorporación de los senadores autonómicos) y un 31,73 puntos entre los electos $(31,27$ con la adición de los autonómicos).

${ }^{14}$ En la Tercera Legislatura deben reseñarse ciertos problemas en la homogeneidad de la Coalición Popular, que no podemos detenernos a comentar; $c f r$. nuestro trabajo Los Grupos parlamentarios en las Cortes Generales (Madrid: Centro de Estudios Constitucionales, 1990), pp. 145 ss.

1534,46 por ciento entre electos y 30,89 por ciento tras la incorporación de los senadores autonómicos, en la Segunda Legislatura y 29,33 por ciento entre electos y 32 por ciento con los autonómicos, en la Tercera.

1627,43 por ciento en la Segunda y 28,43 por ciento en la Tercera.

17 En la Cuarta Legislatura la distancia se mantiene en un 19,72 por ciento y en la Quinta, donde la paridad es mayor, se establece en un 5,14 por ciento.

${ }^{18}$ En la Cuarta Legislatura se reduce la distancia a un 14,91 por ciento entre los electos (un 14,67 incluyendo los autonómicos) y en la Quinta a un 1,44 por ciento (un 1,16 tras la incorporación de los senadores autonómicos). 
Por otro lado, durante bastante tiempo, la composición del Senado no ha planteado problemas graves en el funcionamiento del sistema político y las críticas a su disfuncionalidad, como se ha apuntado, se vinieron centrando en la insuficiencia de las razones que justificaban su pervivencia. La noticia consistía en la ausencia de noticias. En aquellos períodos en los que la fuerza política mayoritaria no alcanzaba por sí misma los 176 escaños en el Congreso o los 130 en el Senado, se recurría a la formación de coaliciones más o menos estables que han garantizado la aprobación de las propuestas gubernamentales en ambas Cámaras.

El único momento de una cierta fricción se produjo al final de la Quinta Legislatura, tras las elecciones autonómicas de mayo de 1995, unos comicios que hicieron evidente la tendencia al alza del Partido Popular. Este partido vio reforzada su posición en la Cámara Alta tras la renovación de los senadores elegidos por las nuevas asambleas de las Comunidades Autónomas. Así se produjo un incremento de los senadores populares hasta los 113 escaños y a una disminución de los socialistas hasta los 111 escaños. En principio, la nueva situación no planteó problemas de inmediato por cuanto continuaban en vigor los pactos de gobierno con los que se inauguró la Legislatura, especialmente, entre el PSOE, Coalición Canaria y Convergencia i Unió. Pero, todo se complicó cuando Convergencia i Unió decidió romper el acuerdo de apoyo al Gobierno y entonces surgió el primer conflicto institucional en el que el Senado adquirió una cierta relevancia. La Mesa del Senado, reflejo de la nueva situación política, en la sesión de 29 de noviembre de 1995, acordó no admitir a trámite la declaración de urgencia realizada por el Gobierno para la tramitación del Proyecto de Ley Orgánica sobre la regulación de la interrupción voluntaria del embarazo, conforme a los artículos 90.3 de la Constitución y 133 del Reglamento del Senado, entendiendo que el Ejecutivo carecía de competencias para realizar tal declaración ${ }^{19}$.

La diferencia de mayorías no dio lugar a problemas sucesivos en la medida que el Gobierno disolvió las Cortes Generales y convocó unas nuevas elecciones generales a través del Real Decreto 1/1996, de 8 de enero ${ }^{20}$.

19 El Gobierno interpuso contra el acuerdo de la Mesa un conflicto de atribuciones que fue resuelto por el Tribunal Constitucional favorablemente a sus pretensiones cuatro años después por Sentencia 234/2000, de 3 de octubre; por lo que ha tenido una limitada eficacia en la solución de la controversia.

20 BOE de 9 de enero de 1996. 


\section{LAS PAUTAS APUNTADAS EN LA SÉPTIMA LEGISLATURA}

Las críticas sobre el Senado han arreciado a partir de ciertos comportamientos que se han venido observando en la Séptima Legislatura, en la que ha dejado de ser una Cámara invisible para convertirse en la destinataria de las principales censuras dirigidas contra el modelo parlamentario español.

La singularidad de la actitud del Senado se torna más llamativa en la medida que se verifica dentro de una situación alejada de los parámetros que le había prefigurado la doctrina y que apartaba a la Cámara del papel que había venido consolidando en la práctica del bicameralismo español. En primer lugar, porque la relevancia se adquiere en un momento en el que el partido del Gobierno cuenta con una respetable mayoría absoluta tanto dentro del Congreso de los Diputados como del Senado y, por lo tanto, no en un panorama de inestabilidad gubernamental, en el que la solidez de la Cámara Alta cumpliese una función de contrapeso a un Congreso políticamente más fragmentado e inseguro. En segundo lugar, como Cámara de contrapeso o "de reflexión" o, si se quiere, de perfeccionamiento de la tarea legislativa, la subsistencia depende bastante de que desempeñe su labor de una manera discreta; si, por el contrario, se convierte en un foco de frecuente controversia, ello puede aumentar la perplejidad de la opinión pública y las dudas sobre la utilidad de conservar una Cámara problemática.

En las últimas ocasiones, cuando el Senado se ha convertido en objeto de atención de los medios de comunicación se ha debido bien a que se estuviese discutiendo una vez más entre las fuerzas políticas sobre la necesidad de proceder a su reforma, o bien por la alarma que entre la opinión pública y la doctrina ha venido originando que se introdujesen ciertas modificaciones por el grupo mayoritario de consumo con el Gobierno dentro algunos textos normativos, aprovechando el momento de la tramitación por esa Cámara.

Quizás el caso más llamativo hasta la fecha haya sido la utilización de la tramitación parlamentaria en el Senado de un proyecto de Ley Orgánica para introducirle a través de enmiendas, presentadas por el Grupo Parlamentario Popular en la Comisión de Justicia ${ }^{21}$ y anunciadas con

${ }^{21}$ El texto de la enmienda se encuentra en el BOCG, Senado, serie II, 171 (c), de 2 de diciembre de 2003. Para que las enmiendas se pudiesen tramitar, con carácter previo resultó preciso ampliar el plazo para la presentación de enmiendas; la resolución se encuentra en BOCG, Senado, serie II, 171 (b), de 26 de noviembre de 2003. 
anterioridad por el Gobierno ${ }^{22}$, el texto normativo de unos artículos que se añaden al Código Penal en los que se tipifican como delito ciertas conductas realizadas por funcionarios públicos ${ }^{23}$. El proyecto de Ley Orgánica que se estaba tramitando y al que se incorporaron tales enmiendas se elaboraba para, a través de una reforma de la Ley Orgánica del Poder Judicial, adaptar esa norma a las necesidades que se derivaban de la aprobación de una nueva Ley de Arbitraje. La incoherencia de la medida llega hasta el extremo de hacer necesario que se procediese a renombrar el "Proyecto de Ley Orgánica complementario a la Ley de Arbitraje, por la que se modifica la Ley Orgánica del Poder Judicial», que recibió, también mediante enmienda, la denominación de «Proyecto de Ley Orgánica del Poder Judicial y del Código Penal $»^{24}$. En consecuencia al final no quedaba nada claro si se trataba de una nueva iniciativa, que surgía a partir de la anterior, algo imposible en el procedimiento legislativo constitucionalizado, y, por supuesto, carecía por su contenido de relación con el objeto del Proyecto de Ley Orgánica modificado.

También, en otra línea, ha sido destacado el papel desempeñado por el Senado en otro asunto de pésima técnica legisladora que se viene repitiendo con periodicidad anual: la tramitación y aprobación de esa norma, especie de "carro portamaletas", que recibe el título de "Ley de Medidas Fiscales, Administrativas y del Orden Social" y que acompaña como una sombra al proyecto de Ley de Presupuestos Generales del Estado. En cada ocasión, durante la tramitación parlamentaria en la Segunda Cámara se han introducido enmiendas dirigidas a la regulación de cuestiones de cierta importancia, sin que el Congreso haya tenido ocasión de discutir y aprobar su contenido, disponiendo tan sólo del trámite de aceptación o rechazo cuando han regresado para su ratificación.

Por dejar constancia de dicha práctica se pueden enumerar algunos significativos ejemplos. En el Proyecto de medidas para el año 2001 se

${ }^{22} \mathrm{El}$ contenido de la reforma fue presentado en el Consejo de Ministros celebrado el 28 de noviembre de 2003 por el Ministro de Justicia y aprobada su tramitación a través de la reforma del proyecto de Ley Orgánica que se encontraba en el Senado, cfr. El Pais, de 29 de noviembre de 2003.

${ }^{23}$ Se incorporan a la Ley Orgánica reguladora del Código Penal los arts. 506, bis, 521 , bis y 576, bis.

${ }^{24}$ El Informe de la Ponencia de la Comisión de Justicia del Senado, en el que se aceptan las enmiendas y se recalifica el texto normativo, se encuentra en BOCG, Senado, serie II, 171 (d), de 3 de diciembre de 2003. Mientras que el Dictamen de la Comisión y la referencia a la aprobación por el Senado se encuentran respectivamente en BOCG, Senado, serie II, 171 (e), de 5 de diciembre de 2003 y BOCG, Senado, serie II, 171 (f), de 12 de diciembre de 2003. 
"crearon" de manera completa las escalas profesionales de los Organismos Públicos de Investigación dependientes del Ministerio de Ciencia y Tecnología y el régimen del Cuerpo Único de Notarios ${ }^{25}$. En el Proyecto de 2002 se introdujeron el impuesto indirecto sobre las ventas minoristas de determinados hidrocarburos, cuya recaudación se debía destinar a sufragar el gasto sanitario y que, en parte, se cedía a las Comunidades Autónomas, y la tasa de seguridad del transporte ferroviario de viajeros; pero, además, se privó de subvenciones electorales a ciertos partidos y se suspendió la ejecución de las sentencias sobre las mismas, cuando los electos por esas fuerzas políticas no hubiesen tomado posesión de sus cargos o en sus listas apareciesen condenados por delitos relacionados con la actuación de bandas armadas ${ }^{26}$. En el Proyecto de 2003 se incluyeron la tasa por el ejercicio de la potestad jurisdiccional en los órdenes civil y contencioso-administrativo, la metodología para la aprobación y modificación de la tarifa eléctrica, los criterios del sistema para indemnizar a los inversores (consecuencia del escándalo de Gescartera), el Plan Nacional de la Televisión Digital Local y los procedimientos para su concesión y el cambio de criterios sobre el accionariado de las televisiones privadas, el régimen de incompatibilidades y otras cuestiones relacionadas ${ }^{27}$. Y en el Proyecto para 2004, además de las reformas realizados en el articulado del Decreto Legislativo de Ley de Tráfico y Seguridad Vial, que adquirieron cierto eco periodístico, se han incluido en su articulado la transposición de la Directiva 2000/60/CE por la que se establece un marco comunitario de actuación en el ámbito de la política de aguas, lo que a su vez ha requerido la derogación y la reforma parcial de la Ley 10/2001, de 5 de julio, del Plan Hidrológico Nacional; se ha introducido un régimen fiscal especial para el acontecimiento "Copa América 2007", así como otras reformas sobre contratos laborales, bonificaciones y ventajas jurídicas de otra naturaleza relacionadas con ese evento deportivo; se han introducido diversas normas sobre televisiones locales, televisión privada y radiodifusión digital; $y$, en fin, se han tomado medidas para la ampliación temporal del Plan Prever ${ }^{28}$.

${ }^{25}$ Cuerpo que, por cierto, continuando con la corrección técnica en la labor legislativa se había creado a través de la Disposición Adicional 24 de la Ley de medidas fiscales, administrativas y del orden social de 1999 (Ley 55/1999, de 29 de diciembre). Las enmiendas se pueden ver en el BOCG, Congreso de los Diputados, 17-9, de 20 de diciembre de 2000.

${ }^{26}$ Los textos de las novedades se pueden consultar en BOCG, Congreso de los Diputados, serie A, 50-12, de 19 de diciembre de 2001.

27 El contenido de las novedades se localiza en BOCG, Congreso de los Diputados, serie A, 112-10, de 19 de diciembre de 2002.

28 Puede consultarse para constatar estas innovaciones el BOCG, Senado, serie II, 173 (g), de 11 de diciembre de 2003. 
El listado descrito, que supone una mínima parte de la complejidad y heterogeneidad que suele manifestar el contenido de estas Leyes, puede considerarse o síntoma de una proverbial imprevisión del Gobierno, que se ve impelido a última hora a poner en vigor normas y hacer funcionar instituciones sobre las que no había reparado cuando hizo su previsión de calendario legislativo, o, lo que parece más cierto, un uso abusivo del derecho de enmienda en el Senado y un sistemático intento de privar a la opinión pública de un debate general y amplio en el tiempo sobre ciertas medidas y a las Cortes de la plena capacidad para ejercer sus competencias constitucionales.

De manera razonable se puede aceptar que, impelido por la doctrina del Tribunal Constitucional sobre la naturaleza de la Ley Presupuestaria, se convierte en imprescindible el recurso a una norma de alubión como la vulgarmente conocida por "Ley de Acompañamiento", o que en ocasiones la complejidad del sector social regulado y del régimen jurídico que lo ordena pueda requerir la tramitación de una sola norma con la que se proceda a la alteración de diversos textos legales ${ }^{29}$. Lo que no queda tan claro es que, primero, cuestiones tan relevantes como las enumeradas, con una entidad y unidad tan claras no sean objeto de tramitación separada a través de propuestas legislativas independientes; segundo, que su novedad no llegue a romper el principio constitucional de que todo proyecto y proposición de ley se debe tramitar y aprobar en primer lugar por el Congreso de los Diputados (arts. 87.2, 88.1, 89.2 y 90.1 de la Constitución); tercero, que una vez que se tramitan se oculten al gran debate parlamentario que, sin duda, tiene ocasión durante el paso de la iniciativa por el Congreso de los Diputados, comenzando por el debate de totalidad, que acaba adquiriendo una especial significación en el caso de las disposiciones presupuestarias anuales; $y$, cuarto, que importe tan poco la conexión del contenido de las "enmiendas" introducidas en el Senado con el objeto del proyecto de ley, lo que no se puede considerar un elogio cuando nos referimos a una norma definida precisamente por su diversidad ${ }^{30}$.

${ }_{29}$ Un ejemplo reciente de este tipo de normas puede ser el Proyecto de Ley Orgánica 21/2003, de 20 de noviembre, de reforma de la Ley Orgánica 4/2000, sobre derechos y libertades de los extranjeros en España y su integración, que en el mismo bloque exigió la reforma de la Ley 7/1985, de 2 de abril, reguladora de las Bases de Régimen Local, de la Ley 30/1992, de 26 de noviembre, de Régimen Jurídico de las Administraciones Públicas y del Procedimiento Administrativo Común y de la Ley 3/1991, de 10 de enero, de Competencia Desleal.

30 Una meditada crítica al abuso que suponen las leyes de acompañamiento se encuentra en Luis María Cazorla Prieto: El Congreso de los Diputados (su significación actual), (Pamplona: Aranzadi, 1999); y Las llamadas leyes de acompañamiento presupuestario: sus problemas de constitucionalidad. (Madrid: Marcial Pons, 1998). 
El relieve adquirido por el Senado contradice, en parte, los presagios doctrinales sintetizados en las palabras conclusivas del mencionado trabajo de CARRERAS: "Desde el punto de vista de las competencias legislativas el Senado es básicamente una Cámara de segunda lectura o de enfriamiento, es decir un órgano que permite una mayor reflexión, una nueva oportunidad de negociación o una mejora técnica de leyes que en última instancia deberán ser aprobadas por el Congreso»" ${ }^{31}$. La cuestión sobre la que cabe detenerse es si esa naturaleza y el articulado constitucional justifican el papel privilegiado asumido durante la Séptima Legislatura por el Senado. Más que nada porque al mismo tiempo, según una clara sintomatología, se viene asistiendo a un importante deterioro de la posición de las Cortes Generales en el sistema constitucional de poderes.

El ejercicio de las facultades de la Cámara colegisladora se puede amparar en dos motivos interconectados. De un lado, la naturaleza comúnmente aceptada de Cámara de reflexión supone que una gran parte de su tarea venga constituida por la corrección de las deficiencias y lagunas que hayan pasado desapercibidas durante la tramitación anterior del texto de la iniciativa legislativa. De otro lado, el cumplimiento de esa función se ejecuta a través del legítimo ejercicio de las facultades de "introducir enmiendas" que el Senado tiene constitucionalmente atribuidas (art. 90.2 de la Constitución).

En torno a la primera de las argumentaciones, y manteniendo nuestra exposición en el estricto marco de los ejemplos aportados, no deja de contener cierto grado de cinismo el sostener que las leyes de medidas fiscales, administrativas y del orden social presentan lagunas, cuando no se conoce a ciencia cierta cuál debe ser su contenido y cuando algunas de sus partes difícilmente se ajustan a la finalidad de permitir la adecuada aplicación de las previsiones contables de los presupuestos; es decir, no existe una regla de oro sobre qué debe y no debe estar ordenado en su articulado y, así, difícilmente se pueden precisar las carencias o los excesos materiales de su articulado. Y, con respecto a la adenda al Código penal que se ha introducido de forma parasitaria en una Ley Orgánica de contenido ajeno, resulta aún más complicada la defensa de que la acción del legislador viene exigida por la naturaleza o el fin de la norma en la que se inserta ${ }^{32}$.

31 «El Senado en la Constitución española», cit., p. 34. Añadía, poco después, que «además la práctica política de estos últimos años ha situado al Senado en una posición todavía más marginal de lo que sería deducible si tuviéramos sólo en cuenta el puro texto constitucional» (p. 35).

32 Algún autor ha denominado este tipo de acto como "Decreto-Ley del Senado». No resulta este trabajo el lugar adecuado para ahondar en la reflexión del 
Sobre la segunda cuestión tanto la Constitución (art. 90), como el Reglamento del Senado permiten que frente a los textos aprobados por el Congreso de los Diputados se presenten enmiendas y propuestas de veto, es decir, enmiendas sobre un texto que ya existe y ha sido contrastado en un dilatado debate previo en la Cámara de diputados y rechazos de la totalidad del texto. La introducción en la fase legislativa senatorial de una regulación completa de una institución conculca, el ya aludido, principio constitucional de precedencia del Congreso de los Diputados en la tramitación y aprobación de los textos legislativos provengan de donde provengan y con independencia de quién sea su autor, priva a la opinión pública del conocimiento del articulado y de los problemas que suscita el proyecto y proposición de ley en cuanto que suprime, de hecho y por completo, la primera parte del procedimiento legislativo y, por último, limita las facultades de decisión del Congreso de los Diputados, la Cámara de representación general, favoreciendo al Senado, la supuesta Cámara de representación territorial, a la que la propia norma constitucional a través de una nítida decisión constituyente concede un papel secundario, que no irrelevante, en el ejercicio de las competencias constitucionales de las Cortes Generales.

Las formas de proceder descritas aparentemente no rompen la regularidad del procedimiento de creación de la Ley, pero en la práctica suponen una quiebra de la finalidad del procedimiento legislativo y, lo que resulta más preocupante, de la posición de las propias Cortes en la aprobación de las leyes y los presupuestos del Estado. Con el agravante de que esa herida se infiería a una institución que en la última legislatura sistemáticamente ha visto erosionarse su posición constitucional y ha perdido relevancia el ejercicio de sus competencias dentro del marco del sistema político implantado por la Constitución.

En apenas veinticinco años de experiencia constitucional democrática se habían consolidado unas reglas que definían las relaciones entre el Gobierno y el Parlamento; subordinando la posición de éste a la voluntad de aquél. Pero los aspectos más criticables de sus rasgos fundamentales parece que se han acentuado y complicado por diferentes motivos durante la Séptima Legislatura. Ya no se trataba únicamente de

contrasentido que supone el hecho de que unas iniciativas especialmente protegidas en su creación por el articulado constitucional (exclusión de la delegación en comisión y en el Gobierno la regulación de las materias que la norma fundamental les reserva, arts. 75.3 y 82 y la intangibilidad de sus materias a la intervención del Decreto-Ley, art. 86.1, la exigencia de mayorías cualificadas y tramites diferenciados del procedimiento legislativo ordinario), se vea debilitada por la invención de un procedimiento ad hoc. 
la tendencia cancilleral que la propia ordenación constitucional confería a la posición del Gobierno, exagerada por la concurrencia de un Ejecutivo que cuenta con mayoría absoluta en ambas Cámaras, ni de la preeminencia que tiene atribuida en sus relaciones con las Cortes Generales, o del papel que ha adquirido la función de dirección política gubernamental en los, en términos de PoRRAS NADALES, "Estados postsociales", sino de un desarme sistemático y, parece que, conscientemente buscado de la institución parlamentaria. Por otro lado, no se trataba tampoco de la reconsideración a la que se ha sometido el papel de los parlamentos en el marco del proceso de racionalización abordado por el constitucionalismo del siglo Xx. Parece que nos podemos encontrar ante algo más profundo.

En el último mandato se ha hurtado al debate y la aquiescencia parlamentaria la intervención de nuestro país en un conflicto bélico, hemos asistido a la selección y renovación de los Presidentes de ambas Cámaras a partir de una declaración de voluntad manifestada por el Presidente del Gobierno, se ha producido un incremento exponencial del contenido de la "Ley de Acompañamiento" a los Presupuestos Generales del Estado y se ha consolidado la práctica de tramitarla como una ley ordinaria, pero disfrutando de los privilegios atribuidos por la Constitución para la ley presupuestaria, se ha negado la constitución de una comisión de investigación para proceder al análisis de, según términos gubernamentales, la "mayor catástrofe ecológica" soportada jamás por nuestro país, se ha instrumentalizado al Congreso para legitimar el proceso judicial de disolución de un partido político conforme al nuevo procedimiento previsto en la Ley Orgánica 6/2002 y, al tiempo, pese a que se trataba de una fuerza política de ámbito básicamente territorial, el Senado no participó en dicho pronunciamiento, y, por último, se ha verificado el proceso de emergencia del Senado que se viene comentando.

En definitiva, el resultado de conjunto ha supuesto un despotenciamiento de las Cortes y un reforzamiento de la posición del Ejecutivo.

El panorama expuesto permite apuntar ciertas conclusiones sobre la regularidad del comportamiento de la Cámara colegisladora en ese período. La primera, y más evidente, el Senado se convirtió en una especie de palanca en manos del Gobierno con la que se ahondaba en la erosión del papel institucional de las Cortes Generales. La segunda, que el reforzamiento de la Cámara alta en ciertas parcelas del ejercicio de la potestad legisladora contradecía la posición que imaginó para ella el Constituyente, según se infiere de la lectura de los diarios de sesiones de las Cortes Constituyentes, y según se plasmó en el articulado cons- 
titucional: el de Cámara de garantía que, con un papel secundario, completase la voluntad de las Cortes, es decir, el papel que ha desempeñado mejor que peor hasta la Séptima Legislatura. La tercera, que ese papel preponderante se ha resaltado en un período parlamentario en la que la mayoría absoluta existente en ambas Cámaras no ponía en peligro la estabilidad gubernamental; por lo que se hacía más evidente el juego de selección gubernamental que libremente optaba por el uso de una u otra Cámara según su conveniencia. Un modelo de bicameralismo que encaja con el previsto, por ejemplo, en la Constitución Italiana, pero que encuentra importantes frenos en la Constitución española. La cuarta, relacionada con la anterior, que cuando se hacen ciertas maniobras en el procedimiento legislativo se están contraviniendo principios constitucionales como el de la primacía legisladora del Congreso; ente afectado cuando no se le permite actuar como Cámara de primera lectura y cuando se le priva de ser destinatario originario en la tramitación de todas las iniciativas legislativas.

\section{LA SITUACIÓN ABIERTA TRAS LAS ELECCIONES GENERALES DE 14 DE MARZO DE 2004}

El panorama descrito apuntaba a la conformación de un nuevo modelo de relaciones intraparlamentarias e interorgánicas con fuerza suficiente como para consolidar una especie de mutación constitucional en el sistema bicameral español. No ha llegado a ser así, puesto que la realidad política ha sufrido un completo cambio tras las elecciones generales del 14 de marzo de 2004, que han alumbrado una nueva configuración política de las Cortes Generales con mayorías diferentes cada Cámara.

Composición en la VIII Legislatura

\begin{tabular}{l|c|c}
\hline & Socialistas & Populares \\
\hline Congreso de los Diputados & 168 & 148 \\
\hline Senado $\left(^{*}\right)$ & $\mathbf{8 1}(96)$ & $102(126)$ \\
\hline
\end{tabular}

* En negrita los electos y entre paréntesis los puestos definitivos tras el nombramiento realizado por las Asambleas legislativas de las Comunidades Autónomas.

Por primera vez, en la Octava Legislatura los dos principales partidos controlan un porcentaje mayor de escaños en el Congreso de los Diputados que en el Senado. Socialistas y populares son "dueños» de 
316 escaños $^{33}$, lo que supone dominar un 90,28 por ciento de escaños en la Cámara baja; sin embargo, tan sólo han conseguido 183 puestos entre los senadores electos, un 87,98 por ciento, y un total 222 asientos $^{34}$, lo que hace descender el porcentaje hasta el 87,71 por ciento de senadores.

También por primera vez la distribución de fuerzas entre ambas Cámaras anuncia problemas para su entendimiento. En el Congreso de los Diputados, el Partido Socialista ha obtenido una mayoría relativa que supone el 46,85 por ciento de los escaños de la Cámara, frente al 42,28 por ciento controlado por el Partido Popular; ambos se encuentran separados por apenas un 4,57 puntos. En cambio, en el Senado nos encontramos con una diferencia inversa, controlando los populares el 49,03 por ciento de los puestos por elección (el 48,64 por ciento de los escaños totales), frente al 38,94 por ciento de los socialistas (el 37,06 por ciento en la composición total) y encontrándose ambas fuerzas separadas por 10,09 puntos $(11,58$ computando tanto los escaños electivos como los designados por las Asambleas de las Comunidades Autónomas). Por cuestiones de radiografía electoral, que no constituyen objeto de este trabajo, la proporcionalidad del sistema electoral del Congreso no ha evitado, como ocurriera con las mayorías socialistas, una alternancia suave, mientras que en la composición del Senado no se ha producido la transformación, el fenómeno de vuelco que se refleja en la otra Cámara. El resultado obtenido en el Senado puede resultar llamativo si se olvida que en la Séptima Legislatura existía una distancia de 31,27 puntos favorable al Partido Popular que se ha erosionado casi en la misma proporción que en el Congreso ${ }^{35}$.

Las consecuencias de esta nueva realidad política para el hilo conductor de este trabajo resultan evidentes. Las tensiones entre Cámaras han dejado de ser previsibles para convertirse rápidamente en una realidad. El Gobierno ha venido marcado por la mayoría preponderante en el Congreso de los Diputados. En esa Cámara el PSOE se ha quedado a 12 escaños de la mayoría absoluta, lo que le permite llegar a

${ }^{33}$ Entre los dos principales partidos controlan el mayor número de escaños en el Congreso de los que han sido titulares en todas las legislaturas anteriores. Los números son, recuérdese, 289 diputados en la Primera, 308 en la Segunda, 268 en la Tercera, 281 en la Cuarta, 300 en la Quinta, 295 en la Sexta y 304 en la Séptima.

${ }^{34}$ No es la mayor cifra de escaños controladas por ambos partidos en el Senado a lo largo de la historia parlamentaria reciente. Fue durante la Sexta Legislatura en la que populares y socialistas coparon 230 escaños de los 259 del Senado.

${ }^{35}$ En el Congreso la distancia favorable al Partido Popular era de 15,43 puntos que se ha transformado en una ventaja de 4,57 a favor del Partido Socialista. 
acuerdos con diferentes fuerzas políticas para hacer avanzar el cumplimiento del programa de gobierno. En el Senado también son factibles consensos que permitan la validación de las cuestiones aprobadas en la otra Cámara; de hecho, el Partido Popular goza de una mayoría relativa que se queda a cuatro escaños de los 130 votos que determinan la mayoría absoluta y la lógica lleva a que los 16 senadores integrantes del Grupo Parlamentario Entesa Catalana de Progrés vote coordinadamente con los 96 del Grupo Parlamentario Socialista. Pero, la aritmética parlamentaria hace más complicados los resultados, porque esta regla última no se cumple de manera automática y con un simple acuerdo alternativo de los senadores del Grupo Popular con los cuatro integrantes del Grupo de Coalición Canaria o con los seis parlamentarios del Grupo Catalán en el Senado de CiU, que han sido socios de gobierno en las Sexta y Séptima Legislaturas, aseguran una mayoría absoluta frente a la que apoya al actual Gobierno y suficiente para que por primera vez en nuestra historia constitucional reciente resulte viable que prospere un veto senatorial a una proposición o un proyecto de ley aprobado en el Congreso de los Diputados (art. 90.2 y 3 CE).

A esa realidad ha contribuido también una característica propia de la configuración constitucional de nuestro Senado, que es consecuencia del diferente tempo electoral de las diversas convocatorias. El cambio de tendencia reflejado en el Senado después de las elecciones autonómicas de 1995 marcaron, junto a otros factores de naturaleza política, la disolución anticipada de las Cortes Generales y el fin de la Quinta Legislatura; las nuevas Cámaras reflejaron en su composición la nueva realidad electoral del país. En esta ocasión, se ha producido un fenómeno inverso, pues la configuración electoral dibujada por las elecciones autonómicas del año 2003 ha hecho que se siga manteniendo una ventaja en los resultados favorable al Partido Popular; la consecuencia ha sido que mientras que los populares se han visto recompensados con 24 senadores de extracción autonómica, los socialistas sólo han recibido 15, sin computar los designados por el Parlamento de Cataluña que pertenezcan al PSC y se integren en el Grupo de Entesa. Salvo en la Quinta Legislatura en la que el principal grupo de la oposición obtuvo en sus inicios dos senadores más que el grupo del gobierno (12 populares y 10 socialistas) ${ }^{36}$, en el resto de los mandatos siempre la fuerza mayoritaria ha recibido un mayor número de senadores autonómicos

${ }^{36}$ En la Segunda Legislatura socialistas (mayoría gubernamental) y los populares recibieron cada uno cuatro senadores autonómicos en los inicios de la Legislatura. El dato no resulta significativo porque en ese momento sólo funcionaban tres Parlamentos, al encontrarse aún en construcción el Estado Autonómico. 
que la principal de la oposición ${ }^{37}$. Esa circunstancia adquiere especial importancia cuando la diferencia de los resultados electorales es ajustada y, como en esta ocasión, no se pueden compaginar las consultas electorales para homogeneizar los resultados.

La conflictividad derivada de las diferentes mayorías no se ha hecho esperar y se ha manifestado tanto a través de la labor frenética de consenso previo que acompaña a toda decisión plenaria como con las derrotas sufridas por las "fuerzas gubernamentales" en ciertas votaciones sensibles que han tenido lugar en los mismos inicios de la Legislatura. Por ahora, el caso más sonado se produjo en la sesión plenaria de 12 de mayo de 2004, en la que tras dos votaciones en el mismo sentido se aprobó por mayoría una moción del Grupo Parlamentario Popular por la que se instaba al Gobierno a no suspender la aplicación de ciertos contenidos de la Ley Orgánica 10/2002, de 23 de diciembre, de Calidad de la Educación ${ }^{38}$; la derrota fue corregida por una contramoción presentada por el Grupo Parlamentario Socialista y aprobada con una enmienda del Grupo Parlamentario Catalán en el Senado, en la siguiente sesión plenaria ${ }^{39}$.

Las páginas anteriores, simplificando bastante, dejan constancia de tres modelos de Senado que se han ido manifestando de forma preponderante en diferentes etapas de la historia constitucional reciente. Un primer modelo de Senado debilitado, que ha interiorizado su papel de, como destacaban CHUECA y PUNSET ${ }^{40}$, órgano instrumental de ampliación del campo del control gubernamental, de oposición y trasmisión de reclamaciones sociales, que ocasionalmente ha permitido la corrección, pactada o no, del contenido de decisiones previamente tomadas en el Congreso. A este tipo senatorial en distintos momentos, usando técnicas diversas, se le ha intentando, con escaso éxito, reforzar su faceta e implicación territorial (con la creación de grupos territoriales, con la creación de la Comisión General de las Comunidades Autónoma, la consolidación del debate sobre "el estado de las Autonomías», etc.). Un segundo mo-

3723 frente a 1 en la Tercera, 16 frente a 9 en la Cuarta, 21 frente a 16 en la Sexta y 23 frente a 8 (sin contar los de Entesa) en la Séptima.

38 Las escaramuzas parlamentarias encuentran constancia en el DSS, Pleno, 3, de 12 de mayo de 2004, pp. 59 a 61.

39 DSS, Pleno, 4, de 25 de mayo de 2004, pp. 89 a 99. Con posterioridad en la sesión del 15 de junio de 2004 se produjo otra notoria derrota de las posiciones gubernamentales (El País, de 16 de junio de 2004, p. 20).

40 Ramón PUNSET: "El Senado en la nueva Constitución española», en Revista de la Facultad de Derecho de la Universidad Complutense, 57, p. 159; y Ricardo Chueca: «Teoría y práctica del bicameralismo en la Constitución española», cit., pp. 84-85. 
delo de Senado propiciado especialmente a partir de los años 1998 y 1999, de Cámara artificialmente reforzada en su papel institucional por claros intereses gubernamentales, en el que paralelamente se ha debilitado su papel de catalizador de intereses territoriales. Y, finalmente, un último modelo de Cámara de resistencia, en la que se ha atrincherado el partido que ha perdido las elecciones en marzo de 2004 y que ha apuntado ya su valor de Cámara beligerante con capacidad para retrasar el cumplimiento del programa gubernamental.

La nueva situación abre nuevos interrogantes sobre el futuro del órgano colegislador si se refuerzan los elementos enumerados. La insistente asunción del papel de foco continuo de tensión para el desarrollo del procedimiento parlamentario, en particular, y de la vida política, en general, suscita interrogantes sobre hasta qué punto se puede sobrellevar sin acabar deslegitimando por completo al Senado ante la opinión pública. Otra vez planea el riesgo de que se convierta en una Cámara visible y se le empiece a considerar el origen de gran parte de los problemas de la política nacional. Desde luego la realidad de la Octava Legislatura no la convierten en una de las etapas más afortunada para embarcarse en una reforma del articulado constitucional; salvo que el proceso de consenso sea intenso y fructífero o bien que se desee otorgar a esa Cámara el dudoso honor de torpedear el procedimiento de reforma constitucional y responsabilizarla ante los ciudadanos del fracaso. Esta actitud seguramente pondría en entredicho su continuidad institucional y su legitimidad.

Aunque suponga una obviedad, resulta recomendable que las principales fuerzas políticas con representación parlamentaria procedan a obrar con prudencia y mediten cuidadosamente qué consecuencias pueden tener sus acciones para la futura continuidad del Senado. La experiencia constitucional española ha venido a demostrar que el articulado de la norma fundamental encierra diversos modelos de Senado que han ido cuajando y se han manifestando en distintas etapas, dependiendo de las circunstancias políticas de cada momento. Bastantes de los problemas de la Cámara continúan encontrándose en su deficiente configuración, pero elementos circunstanciales en cada legislatura ha disimulado o acentuado los problemas originarios de estructuración. La multiplicación o el agrandamiento de tales problemas por intereses políticos coyunturales pueden lograr una definitiva desafección ciudadana hacia una institución sobre la que ya resulta difícil transmitir la bondad de los valores que aporta al funcionamiento del sistema político nacional.

Huelva, 20 de julio de 2004 